\title{
A New Approach in Hail Prevention Technique for a Locally Restricted Area
}

\author{
Artashes K. Arakelyan \\ ECOSERV Remote Observation Centre Co. Ltd., Yerevan, Armenia \\ Email: arakelyan ak@yahoo.com, ecoservroc@yahoo.com
}

How to cite this paper: Arakelyan, A.K. (2017) A New Approach in Hail Prevention Technique for a Locally Restricted Area Agricultural Sciences, 8, 559-571.

https://doi.org/10.4236/as.2017.87042

Received: May 29, 2017

Accepted: July 2, 2017

Published: July 5, 2017

Copyright $\odot 2017$ by author and Scientific Research Publishing Inc. This work is licensed under the Creative Commons Attribution International License (CC BY 4.0).

http://creativecommons.org/licenses/by/4.0/

\begin{abstract}
This article describes a new method for hail detection and an autonomous and automatically functioning complex for hail prevention, suppression or trapping for locally restricted application.

\section{Keywords}

Hail, Hail Detection, Hail Prevention and Suppression, Brightness

Temperature, Microwave Radiometer
\end{abstract}

\section{Introduction}

Every year hail and shower cause great and severe damage to agriculture and human properties all over the World. To minimize material damage in size or to prevent economic disruption and downturn in agriculture various kinds of anti-hail protection methods and stations are used. At present several anti-hail protection methods and stations are known in the art. It is known an anti-hail protection technique with an active effect on hail clouds by shells or rockets which seed clouds, spread reagents (more often silver iodide) in clouds [1] [2], which is an expensive and ecologically harmful one. It is known as well an anti-hail protection method with an active impact on hail clouds by significant shock waves directed upwardly to the sky [3] [4] [5] [6] which is a chipper and ecologically harmless one. It is believed that the succession of shock waves transports positive ions from ground level to cloud level which disrupt formation of hail nuclei. This method of anti-hail protection is fulfilled by the following way. Supersonic and significant shock waves is generated by sequential detonating an explosive mixture of combustible gas (fuel) and air in a combustion chamber of a hail preventing sonic generator (gun, cannon) and is directed upwardly to the sky. By selecting material and quantity of the combustible fuel, 
number and duration of detonations it is possible to provide significant shock waves and to effect on the hail clouds up to $10 \mathrm{~km}$ of altitude, changing hail cloud structure, preventing further development of hail and transforming hail into rain or wet snow or small ice drops. As the fuel or combustible gas may be used acetylene gas, a mixture of propane-butane gases or other gas or liquid fuel with high energy capabilities [6]. Both described techniques are not effective against an already formed hailstone, so the most important requirement in their use is their timely startup. Shells or rockets must be fired or launched in cumulonimbus before large hailstones forming. A hail generator operation must be approximately initiated 15 - 20 minutes before hail storm formation or storm arrival. The efficiency of both techniques decreases in proportion to startup delay. If the anti-hail device is activated when the storm is directly above, its efficiency will be very low. Therefore, for both techniques of protection it is strongly recommended to use them in conjunction with either weather radar equipment or at a weather alert subscription service. Usually, for hail detection powerful Weather Doppler radar is used, operating at short centimeter or millimeter band of waves. Although, these radar cost several hundred thousand or millions USD, in dependence of the power and service facilities, they have serious disadvantages and cannot solve the problem totally. The Weather radar may detect and classify with high probability already formed hail clouds, but cannot classify the cloud which may be transformed in hailstorm. Therefore a reason is appeared in development and in production new kind of detector-classifiers which will cost cheaper and will have additional advantages in hail bearing clouds detection and hail prediction.

An anti-hail net is the third technique for hail suppression which is widely employed now together with two mentioned others. The anti-hail net is the only means of protection which is recognized by the insurance companies and which could reduce user's policy. However, this protection is rarely installed to protect some important farms because its installation and handling costs are very expensive for large-area farms. For instance: a 50 -hectare orchards will pay about $250,000 €$ for an installation of the anti-hail net on the entire farm (5000 $€ /$ hectare) and for both handling operations (unroll nets in springtime and roll up in winter) yearly costs will be around 60,000 $€(1200 € /$ hectare/year).

Unfortunately, in spite of its higher cost the anti hail net is not efficient in the event of severe hail storms. Consequences are potentially even worse than for a completely unprotected farm, because if the net's structure collapses on the crops the grower will often be forced to replant the entire afflicted areas. Therefore, it is more reasonable to protect such areas additionally by cheaper cost methods and means of hail suppression and to prevent severe hail using a sonic generator, for instance, which may operate autonomous and automatically.

In this article a new approach for hail early detection is described, as well as a fully autonomous and automatically functioning anti-hail complex is presented which is applicable for hail prevention, suppression or trapping in a locally restricted area. 


\section{A Method for Hail Early Detection}

Experimental researches carried out in Armenia under frameworks of the International Science and Technology Center's (ISTC) Projects A-871 and A-1524 have shown that for hail and for hail bearing clouds (nimbuses) early detection it is possible to use simple microwave radiometers with usual sensitivities. Such radiometers may cost undoubtedly incomparably chip than the Weather radar (about 1000 - 2000 USD in dependence of their operation frequencies) and may solve hail early detection problem not worse than radar. The physical basis of the above mentioned idea is the following. Cloud's brightness temperature is a function of many parameters, in which air and particles temperatures, fraction type (water or ice) and particles size are the principal variables. The changes of cloud's brightness temperature, related with the changes of dielectric properties of particles (water or ice) and air temperature, depend on the frequency of observation. Therefore, by microwave radiometers, which measure intrinsic emission of observed media in radio frequencies, it is possible to make precise and high probable detection and classification of hail and hail bearing clouds. Radiometric observation may not miss the stage of transformation of water vapor and drops of water to hail as well, because water and ice dielectric constants are very differ and such formation's brightness temperatures (powers of their intrinsic emissions) will sufficiently vary one from other.

Really, in Figure 1 the results of radiometric measurements of clear air and clouds (including cumulonimbus) brightness temperatures (more exactly apparent temperatures) are presented measured at various microwave frequencies and polarizations [7] [8]. These measurements were carried out in the experimental site of ECOSERV Remote Observation Centre Company (ECOSEVR ROC), from the measuring complex constructed under the framework of ISTC Projects A-872 and A-1524. The measurements were carried out under various

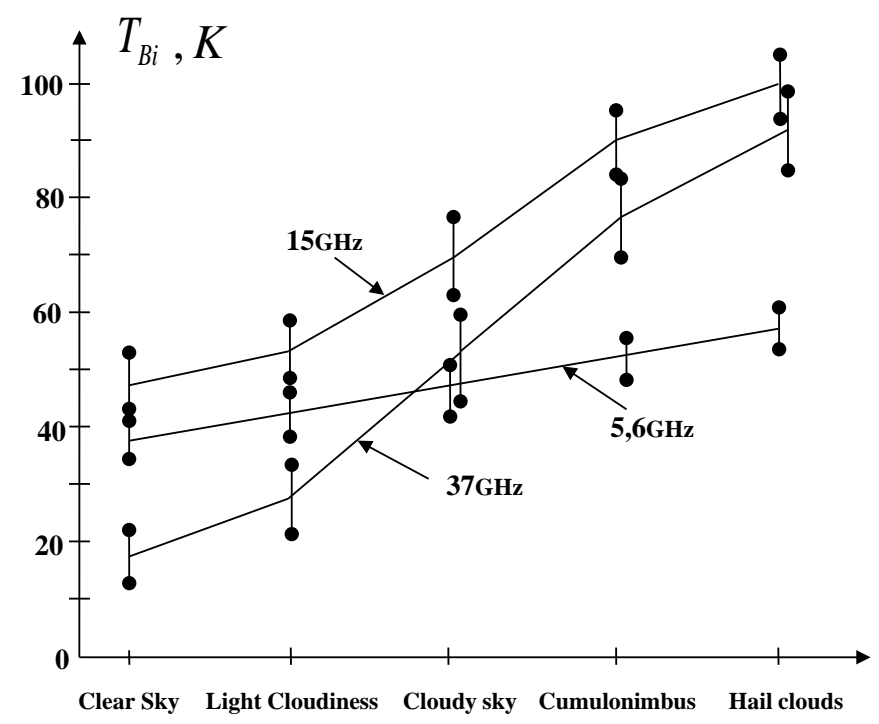

Figure 1. Clear sky and clouds brightness temperatures. 
angles of sensing, at vertical and horizontal polarizations of sensing by radiometric channels of $\mathrm{C}(5.6 \mathrm{GHz}), \mathrm{Ku}(15 \mathrm{GHz})$, and $\mathrm{Ka}(37 \mathrm{GHZ})$ band combined scatterometric-radiometric systems (ArtAr-5.6, ArtAr-15, and ArtAr-37) developed and built by ECOSERV ROC under the framework of the above mentioned ISTC Projects [9] [10] [11] [12]. The results of Figure 1 corresponding to hail clouds are not measured results. They are approximately estimated values obtained from existed theories.

Measured and estimated results of observed sky (clear and cloudy) apparent temperatures $T_{B i}$ presented in Figure 1 have shown that radiometric contrasts due to occasional appearance of a hail cloud on the clear sky may reach up to 20 - $80 \mathrm{~K}$ or more in dependence of the frequency band. This means that microwave radiometers with usual sensitivities $\sim 0.2 \mathrm{~K}$ (C-band), $\sim 0.5 \mathrm{~K}$ (Ku-band) and $\sim 1.0 \mathrm{~K}$ (Ka-band) at $1 \mathrm{~s}$ integration time may be successfully used for hail detection and hail clouds classification. In mass production, such radiometers will cost incomparably cheaper than radar.

\section{A Method of Anti-Hail Protection of a Restricted Area}

The idea to use microwave radiometer for hail and hail bearing clouds early detection, which is very significant for hail prevention and suppression by timely starting up of sonic generators has been initially patented in Armenia as an invention [8] [13]. After that the invention was patented in China [14], in the USA [15], in Canada [16] and in the EU [17]. On the basis of the obtained European Patent the invention is patenting in France, in Germany, in Spain, in Italy, in Switzerland, in the UK and in Turkey. The invention is patenting also in India and in Russian Federation. The application of microwave radiometers will allow implement fully autonomous and automatically functioning anti-hail protection of an area (circle space) of 50 - 70 hectare of a size.

In Figure 2 an outline of a version of implementation of a local network of autonomous and automatically functioning anti-hail protection of the protected area (1) of a limited size is presented. The far-range detector-alerter (2) is used to detect hail clouds or cumulonimbus at distant approaches to the protected area, usually $4-6 \mathrm{~km}$ far to the protected area and to warn the anti-hail protection system (3) about the impending hail danger. It is mounted on the scanner (4) which allows observe sky of the adjacent land under fixed azimuth direction, to rock far-range detector-alerter and to observe sky of the adjacent land within a limited sector of azimuth angles or to rotate far-range detector-alerter and to observe sky of the adjacent land all around the protected area. In Figure 3 a detailed block diagram of the far-range detector-alerter is presented. In Figure 4 a detailed block diagram of the hail prevention system (3) is presented, where the local detector-alerter (12) detects the looming cloud and starts-up the sonic generator (13).

The local network of anti-hail protection of the protected area of limited size, which is a particular case of a general solution fully described in [13]-[17], is implemented by the following way. After initial running of the far-range detector- 


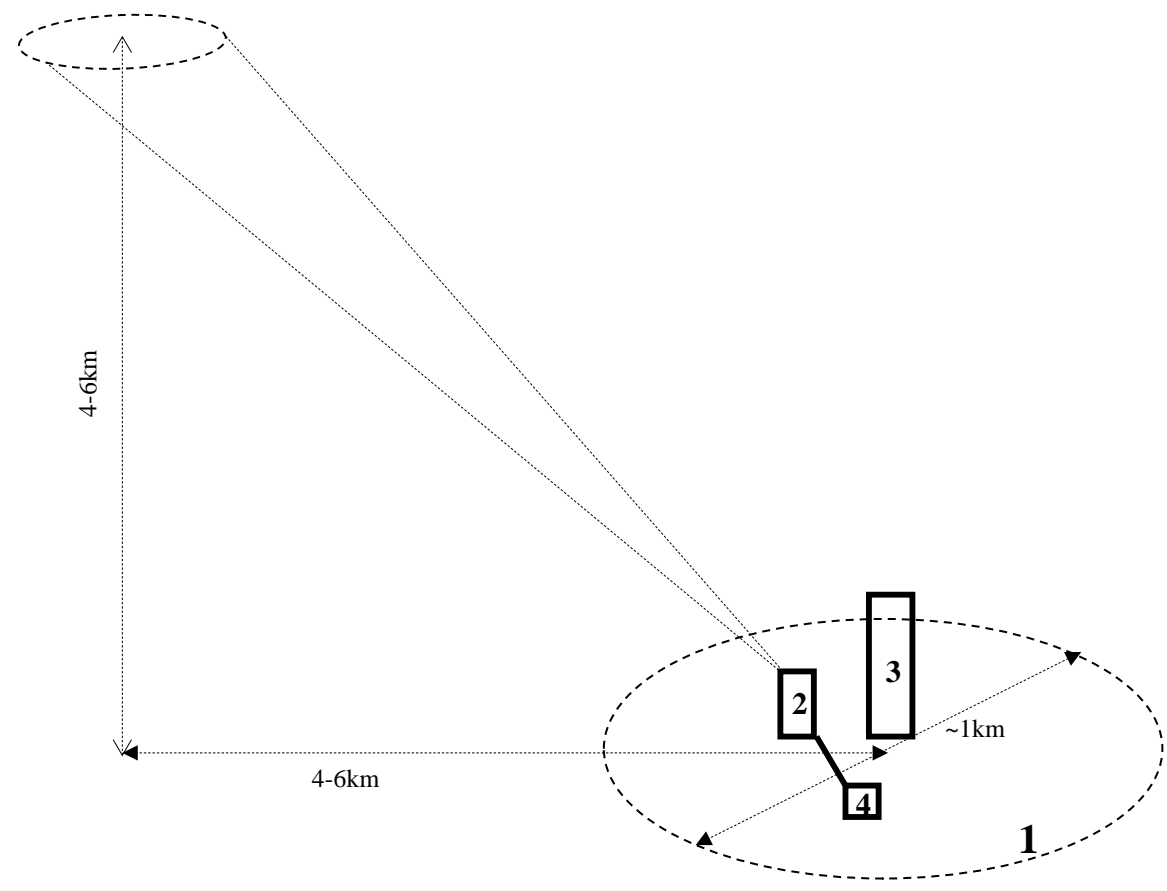

Figure 2. An outline of a version of a local area anti-hail protection 1-a protected area of a limited size, 2-a far-range detector-alerter, 3-a hail prevention system, 4-a scanner.

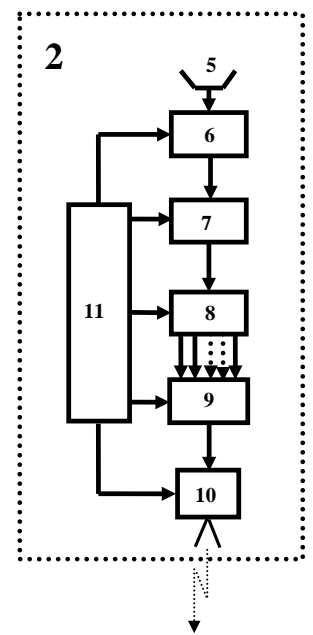

Figure 3. A block diagram of a far-range detector-alerter, 2-a far-range detector-alerter, 5-a far-range antenna, 6-a far-range radiometric receiver, 7-a far-range compensation device, 8-a single-channel thresholder, 9-a far-range warning device, 10-a far-range transmitter, 11-a power supply.

alerter, its scanner and the hail prevention system, that is after switching on power supplies (11 and 20, or 20a and 20b) and opening the mechanical valve (31) of the fuel reservoir (30) the local network of anti-hail protection continues its work autonomous and automatically. The controller (26) opens the solenoid valve (32) and sets the sonic generator (13) in a "waiting mode" of operation. Flow of the combustible gas through the open solenoid valve and the pressure regulator (33) comes to the input of the closed fuel injector (28). 


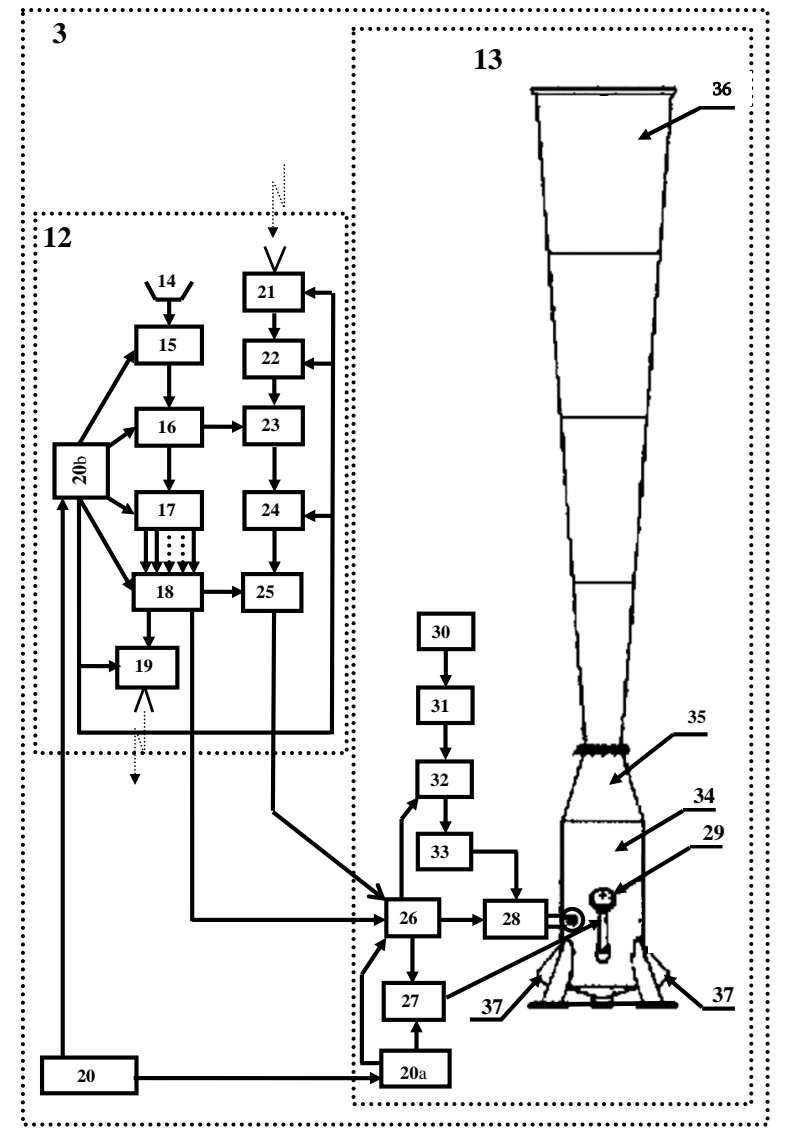

Figure 4. A block diagram of an anti-hail protection system 3-an anti-hail protection system, 12-a local detector-alerter, 13-a sonic generator, 14-an antenna, 15-a radiometric receiver, 16- a compensation device, 17-a multi-channel thresholder, 18-a warning device, 19-a transmitter, 20 (20a and 20b) - a power supply, 21-a receiver, 22-a code comparator, 23-the first controlled switcher, 24-a single-channel thresholder, 25-the second controlled switcher, 26-a controller, 27-an ignition means, 28-a fuel injector, 29-an igniter, 30-a fuel reservoir, 31-a mechanical valve, 32-a solenoid valve, 33-a pressure regulator, 34-a cylindrical combustion chamber, 35-a neck, 36-a conical barrel, 37-inlet ports.

The scanned far-range detector-alerter begins to observe and to measure unceasingly the adjacent land's sky intrinsic microwave emission under specified elevation angle of observation (tilted observation) and approximately up-directed local detector-alerter simultaneously begins to measure unceasingly the protected area's sky intrinsic microwave emission and to listen watch (radio ether) uninterruptedly to receive warning signals about impending hail danger transmitted on the air by the far-range detector-alerter.

The far-range antenna (5) receives continually signals of sky intrinsic microwave emission and transfers them to the input of far-range radiometric receiver (6). The far-range radiometric receiver processes received signals and outputs to the input of far-range compensation device (7) a signal corresponding to a sum of powers of signals of external emissions (sky, surrounding, external interfe- 
rence) and internal noises. The far-range compensation device compensates a part of the incoming signals corresponding to clear air condition of sky observation and outputs remainder of the signals to the input of single-channel thresholder (8). The single channel thresholder compares the remainder of the signals with the "minimum" threshold level and outputs the signal " 1 " to the input of the far-range warning device (9), if its input signal exceeds the "minimum" threshold and the signal " 0 " otherwise. When the far-range warning device receives the signal " 1 ", it generates an alert code-signal on impending hail danger from the adjacent land and outputs the generated alert code-signal to the input of the far-range transmitter (10), which transmits on the air the alert code-signal on impending hail danger from the adjacent land.

Independently of the far-range detector-alerter, the local detector-alerter observes and measures unceasingly the protected area's sky intrinsic microwave emission under specified (near zero) elevation angle of observation. Up-directed or slightly tilted antenna (14) receives continually signals of protected area's sky intrinsic microwave emission and transfers them to the input of the radiometric receiver (15). The radiometric receiver processes received signals and outputs to the input of the compensation device (16) a signal corresponding to a sum of powers of signals of external emissions and internal noises. The compensation device compensates a part of the incoming signals corresponding to clear air condition of sky observation and outputs remainder of the signals to the input of the multi-channel thresholder (17). In the multi-channel thresholder the remainder of the signals is compared with $\mathrm{N}$ various threshold levels in $\mathrm{N}$ single level thresholders. Each single level thresholder outputs the signal "1" to the input of the warning device (18) if its input signal exceeds the respective threshold and the signal " 0 " otherwise. The warning device processes jointly received " 1 " and " 0 " signals, generates a warning code-signal in accordance with the received " 1 " and " 0 " signals and outputs generated warning code-signal to the input of the controller by electrical cords or by means of wireless communication. The controller sets the operation mode of the sonic generator in accordance with the received warning code-signal, such as a "switching-on mode", a "waiting mode", an "operating mode" and a "turning-off mode", and sets operation parameters, such as power (the combustible fuel quantity) and duration of detonations, number (frequency) of detonations and a detonation window. The controller keeps the sonic generator in a "waiting mode" of operation if received warning code-signal has the value " 0 ". When the controller receives a warning code-signal with the value " 1 " or more it sets the "operating mode" of operation of the sonic generator, sets operation parameters of the sonic generator in accordance with the value of the received warning code-signal, generates control signals and runs the sonic generator. Simultaneously with setting the "operating mode" of operation of the sonic generator the transmitter may generate and transmit on the air an alert code-signal about the hail danger in that local area as information for other protected areas or weather services.

When the controller receives the warning code-signal exceeded "maximum" threshold level it sets the "turning-off mode" of operation and switches off the 
sonic generator. The controller switches on the sonic generator and resets the "waiting mode" of operation when it receives from the warning device next (next in turn) signal with the value " 0 " only.

Threshold levels of thresholders (8) and (17) depend on operation frequencies (frequency bands) of radiometric receivers (6) and (15). In Figure 5 frequency dependences of "maximum" and "minimum" threshold levels are presented, where the curve of "minimum" threshold level corresponds to radiometric contrasts frequency dependence of cumulonimbus caused a rainfall with rare hail stones. "Minimum" values of radiometric contrasts of Figure 5 were estimated and approximated from the results of multi-frequency and dual polarization (vertical and horizontal) radiometric measurements carried out under elevation angles $20^{\circ}$ and $30^{\circ}$ of sensing [18]-[24] and from the known theory of passive microwave (radiometric) remote sensing. Theoretical approximations show that these curves are acceptable for elevation angles from the interval $0^{\circ}-30^{\circ}$ as well.

"Maximum" threshold level's frequency dependence of Figure 5 was estimated and approximated from the results of theoretical and experimental researches and corresponds to radiometric contrasts frequency dependence of cumulonimbus caused a hard hail storm which is impossible to prevent by existed technical means.

The receiver (21), which continuously listening watch (ether), outputs received signals to the input of the code comparator (22). The code comparator compares outputs of the receiver with its proper code-signal, corresponding to the alert code-signal of the far-range warning device, and generates an alert signal if the received signal coincides with the alert code-signal transmitted on the air by the far-range transmitter, and a " 0 " signal otherwise.

Output signals of the code comparator come to the controlled terminal (input) of the first controlled switcher (23) which connects together input/output terminals of the first controlled switcher if an alert signal comes to the controlled terminal of the first controlled switcher, and keeps disconnected input/output terminals of the first controlled switcher otherwise. The first controlled switcher

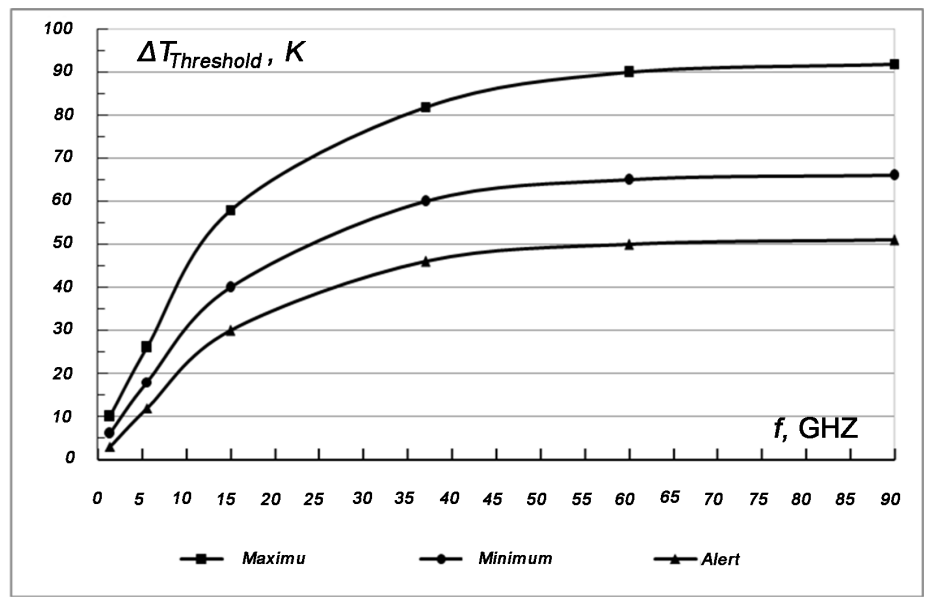

Figure 5. The curves of "maximum", "minimum" and "alert" thresholds frequency dependences. 
with connected input/output terminals connects the output of the compensation device (16) with an input of the single-channel thresholder (24). The singlechannel thresholder compares output signals of the compensation device with the "alert" threshold level and generates an alerting code-signal if the input signal exceeds the "alert" threshold and the signal "0" otherwise. The alerting code-signal passes through the second controlled switcher (25) with joined input/output terminals and from the output terminal of the second controlled switcher goes to the corresponding input of the controller by electrical cords or by means of wireless communication. The controller generates an alert control signal, sets an "alert mode" of operation and starts up the sonic generator in accordance with specified operational conditions of the "alert mode" of operation. The "alert mode" of operation of the sonic generator is turned-off simultaneously with interrupting the alert code-signal. The "alert mode" of operation is turned-off as well simultaneously with setting the "operating mode" or the "turning-off mode" of operation of the sonic generator, when the warning device disconnects input/output terminals of the second controlled switcher.

The alert threshold level depends on operation frequency of the radiometric receiver and in dependence on the frequency band of operation is about $3-15 \mathrm{~K}$ low than the "minimum" threshold level. In Figure 5 a curve of "alert" threshold's frequency dependence is presented as well, estimated and approximated from the results of theoretical and experimental researches [18]-[23]. Radiometric contrasts of Figure 5 are given in Kelvin. Corresponding thresholds values in Volts depend on structure and technical parameters of utilized radiometric receivers (6) and (15) and may be defined from the results of theoretical estimations or from the results of experimental measurements and calibrations. "Maximum", "minimum" and "alert" thresholds levels may be corrected and may be changed individually during the exploitation of the anti-hail protection system (1) by controlled thresholders (8), (17) and (24).

Thus, by this way it is possible to enhance autonomous operation efficiency of the local network of anti-hail protection of the protected area of limited size and to automate its exploitation.

\section{A Method for Hail Trapping}

For some regions, hail or cumulonimbus has a preferred direction and usually comes approximately from the same direction, and sometimes in the surrounding of the protected area one can find places where hail is allowed. These facts can be used to capture hail, to force hail to fall out on a territory where its damage can be relatively small. The method of early hail detection described above makes it possible to implement a completely autonomous and automatically functioning network of hail traps. Such a network can be completely implemented separately or in combination with an implemented network of hail protection, if there are places near or far of the protected area where hail may fall out.

In Figure 6 an outline of a version of realization of autonomous and automatically functioning network for hail capture in hail traps is presented. When 

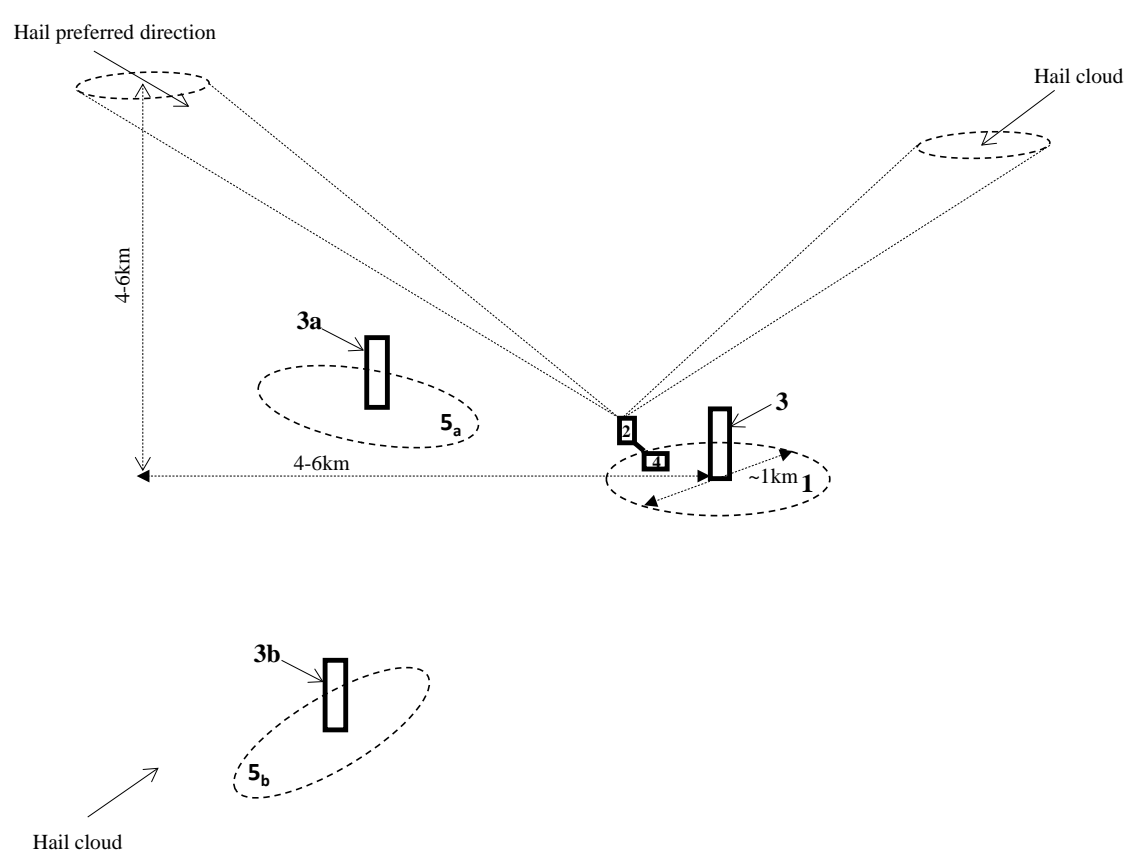

Figure 6. An outlook of a version of realization of traps for hail. 1-a protected area of a limited size, 2-a far-range detector-alerter, 3, 3a and 3b-hail prevention systems, 4-a scanner, $5 \mathrm{a}$ and $5 \mathrm{~b}$-hail trapping areas.

the far-range detector-alerter (2) detects hail cloud or cumulonimbus coming from the preferred or from another direction and warns the local detector-alerter (12a) or (12b) of the anti-hail protection system (3a) or (3b) of the trapping area $(5 a)$ or $(5 b)$ by transmitting on the air warning cods-signals about impending hail danger from the preferred or from another direction, the detector-alerter (12a) or (12b) of the anti-hail protection system (3a) or (3b) sets an "alert mode" of operation and starts up the sonic generator (13a) or (13b) of the anti-hail protection system (3a) or (3b) by the above described way. In the absence of nearby located far-range detector-alerter the anti-hail protection system (3a) or (3b) works separately and uses "minimum" threshold level for setting the "operation mod" of operation for the sonic generator (13a) or (13b) and for transmitting on the air the alert code-signals on impending hail danger from the trapping area $(5 \mathrm{a})$ or $(5 \mathrm{~b})$ for protected areas located far away or for weather services.

When the far-range detector-alerter detects a cloud of severe hail which can approach to the trapping area (5b) from the side of the protected area (1), crossing it, then the anti-hail protection system (3) alarmed by the far-range detector-alerter turn-out the sonic generator (13) of the protected area and skips a hail cloud. Simultaneously, it alarms the anti-hail protection system ( $3 b)$ of the trapping area (5b) by transmitting on the air warning cods-signals about impending hail danger from that azimuth direction, which sets an "alert mode" of operation and starts up the sonic generator (13b) when the signals of sky brightness temperature exceeds the "alert" threshold level. 
Thus, by this way it is possible to implement a fully autonomous and automatically functioning network of spatially distributed hail traps. This is also a particular case of a solution fully described in [13]-[17].

\section{Conclusion}

Thus, microwave radiometers with usual sensitivities may be successfully used for hail detection, clouds classification and for early alerting on impending hail danger. By an application of radiometric detector-alerter it is possible to implement an autonomous and automatically functioning anti-hail protection of a local area of a limited size, as well as to implement a fully autonomous and automatically functioning network of spatially distributed hail traps.

\section{Acknowledgements}

Sincerely grateful to the International Science and Technology Center for financial assistance through ISTC projects A-872 and A-1524 for development microwave devices and carrying out field measurements.

\section{References}

[1] Sulakvelidze, G.K., Kiziriya, B.I. and Tsykunov, V.V. (1974) Progress of Hail Suppression Work in the USSR Chapter 11 of Weather and Climate Modification. Wiley, New York, 410-431.

[2] Federer, B., Waldvogel, A., Schmid, W., Schiesser, H., Hampel, H., Schweingruber, M., Stahel, W., Bader, J., Mezeix, J.F., Doras, N., der Megreditchian, G. and Vento, D. (1986) Main Results of Grossversuch IV. Journal of Climate and Applied Meteorology, 25, 917-957. https://doi.org/10.1175/1520-0450(1986)025<0917:MROGI >2.0.CO;2

[3] Oddie, B.C.V. (1965) The Hail Cannon: An Early Attempt at Weather Control. Weather, 20, 154-156. https://doi.org/10.1002/j.1477-8696.1965.tb02543.x

[4] Morgan, G.M. (1973) A General Description of the Hail Problem in the Po Valley of Northern Italy. Journal of Applied Meteorology, 12, 338-353. https://doi.org/10.1175/1520-0450(1973)012<0338:AGDOTH>2.0.CO;2

[5] Changnon, S.A. and Ivens, J.L. (1981) History Repeated: The Forgotten Hail Cannons of Europe. Bulletin of the American Meteorological Society, 62, 368-375. https://doi.org/10.1175/1520-0477(1981)062<0368:HRTFHC>2.0.CO;2

[6] Ollivier, G. (1995) Anti-Hail Shock Wave Generator. US Patent No. 5381955.

[7] Hambaryan, A.K., Arakelyan, A.K. and Arakelyan, A.A. (2014) The Results of C-, $\mathrm{Ku}-$, and Ka-Band Multi-Frequency Radiometric Measurements of Clear Air and Clouds Brightness (Antenna) Temperatures. Proceedings of the International Conference on Microwave and THz Technologies and Applications, Aghveran, 2-3 October 2014, 49-53.

[8] Arakelyan, A.K., Hambaryan, A.K. and Arakelyan, A.A. (2016) A New Approach in Hail Detection and Prevention. Proceedings of the International Conference IGARSS 2016, Beijing, 10-15 July 2016, 4. https://doi.org/10.1109/igarss.2016.7729131

[9] Arakelyan, A.K., Hambaryan, A.K., Smolin, A.I., Karyan, V.V., Poghosyan, N.G., Sirunyan, M.A., Manukyan, M.R. and Arakelyan, A.A. (2005) Polarimetric, KaBand, Combined, Short Pulse Scatterometer and Radiometer System. Progress in 
Contemporary Radio Electronics, No. 7, 73-77.

[10] Arakelyan, A.K., Hakobyan, I.K., Arakelyan, A.A., Hambaryan, A.K., Grigoryan, M.L., Karyan, V.V., Manukyan, M.R., Hovhannisyan, G.G., Poghosyan, N.G. and Poghosyan, T.N. (2007) Dual-Channel, Polarimetric, Combined Scatterometer-Radiometer at 5.6GHz. Electromagnetic Waves and Electronic Systems, 12, 41-47.

[11] Arakelyan, A.K., Hakobyan, I.K., Arakelyan, A.A., Hambaryan, A.K., Grigoryan M.L., Karyan, V.V., Manukyan, M.R., Hovhannisyan, G.G., Poghosyan, N.G. and Clifford, S.F. (2007) Ku-Band, Short Pulse, Dual-Polarization, Combined Scatterometer-Radiometer. Progress in Contemporary Radio Electronics, No. 12, 41-50.

[12] Arakelyan, A.K., Hambaryan, A.K., Hambaryan, V.K., Karyan, V.V., Manukyan, M.R., Grigoryan, M.L., Hovhannisyan, G.G. and Arakelyan, A.A. (2010) ThreeFrequency and Multi-Polarization Measurements of Bare and Vegetated Soils Microwave Reflective and Emissive Characteristics Angular Dependences by $\mathrm{C}, \mathrm{Ku}$ and Ka-Band Combined Scatterometer-Radiometer Systems. Proceedings of the International Workshop IRPhE 2010, Aghveran, 23-25 September 2010, 131-136.

[13] Arakelyan, A.K. (2013) A Method and a Network of Wide-Ranging Anti-Hail Protection. Armenian Patent No. 2769.

[14] Arakelyan, A.K. (2016) An Automated Wide-Ranging Anti-Hail Protection Method and a Network. Chinese Patent No. ZL2012800716222.

[15] Arakelyan, A.K. (2016) An Automated Wide-Ranging Anti-Hail Protection Method and a Network. US Patent, No. 9491912.

[16] Arakelyan, A.K. (2017) An Automated Wide-Ranging Anti-Hail Protection Method and a Network. Canadian Patent, No. 2862959.

[17] Arakelyan, A.K. (2017). An Automated Wide-Ranging Anti-Hail Protection Method and a Network. European Patent No. 2725893.

[18] Arakelyan, A.K., Hambaryan, A.K., Hambaryan, V.K., Karyan, V.V., Manukyan, M.R., Grigoryan, M.L., Hovhannisyan, G.G., Arakelyan, A.A. and Darbinyan, S.A. (2010) Multi-Frequency and Polarimetric Measurements of Perturbed Water Surface Microwave Reflective and Emissive Characteristics by C-, and Ku-Band Combined Scatterometric-Radiometric Systems, Ocean Sensing and Monitoring II. In: Hou, W. and Arnon, R.A., Eds., Proceedings of SPIE, 7678, 76780C-1-76780C-8.

[19] Grigoryan, M.L., Arakelyan, A.K., Hambaryan, A.K., Karyan, V.V., Hovhannisyan, G.G., Arakelyan, A.A. and Darbinyan, S.A. (2010) Clouds and Rain Effects on Perturbed Water Surface Microwave Reflection and Emission at $37 \mathrm{GHz}$, Ocean Sensing and Monitoring II. In: Hou, W. and Arnon, R.A., Eds., Proceedings of SPIE, 7678, 76780C-1-76780C-8.

[20] Arakelyan, A.K., Hambaryan, A.K., Arakelyan, A.A., Grigoryan, M.L., Karyan, V.V. and Hovhannisyan, G.G. (2011) Frequency and Polarization Peculiarities of Water Surface Radar cross Section and Brightness Temperature Angular Dependences and Their Changes Due to Clouds and Rain. Proceedings of the OCEANS 2011 Conference and Exhibition, Kona, 19-22 September 2011, 9.

https://doi.org/10.23919/oceans.2011.6106901

[21] Grigoryan, M.L., Arakelyan, A.K., Hambaryan, A.K. and Arakelyan, A.A. (2011) Angular and Polarization Measurements of Snow and Bare Soil Microwave Reflective and Emissive Characteristics by Ka-Band $(37 \mathrm{GHz})$, Combined Scatterometer-Radiometer System, Remote Sensing for Agriculture, Ecosystems and Hydrology XIII. In: Chrisopher, M.U., Neale, A.M. and Richter, K., Eds., Proceedings of SPIE 0277-786X, 8174, 81742C-1-81742C-9.

[22] Arakelyan, A.K., Hambaryan, A.K. and Arakelyan, A.A. (2012) Preliminary Results of Radiometric Measurements of Clear Air and Clouds Brightness (Antenna) Tem- 
peratures at $37 \mathrm{GHz}$, Sensing for Agriculture and Food Quality and Safety IV. In: Kim, S.M.S. and Chao, T.K., Eds., Proceedings of SPIE 0277-786X, 8369, 8369031-836903-9.

[23] Arakelyan, A.K., Hambaryan, A.K., Hambaryan, V.K. and Arakelyan A.A. (2012) Preliminary Results of C-, Ku-, and Ka-Band Multi-Frequency Radiometric Measurements of Clear Air and Clouds Brightness (Antenna) Temperatures, Proceedings of the International Workshop IRPhE 2012, Yerevan, 16-17 October 2012, 117-121.

[24] Hambaryan, A.K., Arakelyan, A.K. and Arakelyan, A.A. (2016) The Results of Multi-Frequency Measurements of Clear Sky and Clouds Apparent Temperatures. Proceedings of the International Conference IGARSS 2016, Beijing, 10-15 July 2016, 4.

Submit or recommend next manuscript to SCIRP and we will provide best service for you:

Accepting pre-submission inquiries through Email, Facebook, LinkedIn, Twitter, etc. A wide selection of journals (inclusive of 9 subjects, more than 200 journals)

Providing 24-hour high-quality service

User-friendly online submission system

Fair and swift peer-review system

Efficient typesetting and proofreading procedure

Display of the result of downloads and visits, as well as the number of cited articles

Maximum dissemination of your research work

Submit your manuscript at: http://papersubmission.scirp.org/

Or contact as@scirp.org 